\title{
Oxic and anoxic conditions affect arsenic (As) accumulation and arsenite transporter expression in rice
}

by Wu, C., Huang, L., Xue, S., Pan, W., Zou, Q., Hartley, W. and Wong, M.

Copyright, Publisher and Additional Information: This is the author accepted manuscript. The final published version (version of record) is available online via Elsevier Please refer to any applicable terms of use of the publisher.

DOI: http://dx.doi.org/10.1016/j.chemosphere.2016.10.114

Harper Adams

University

Wu, C., Huang, L., Xue, S., Pan, W., Zou, Q., Hartley, W. and Wong, M. 2016. Oxic and anoxic conditions affect arsenic (As) accumulation and arsenite transporter expression in rice.

Chemosphere.

4 November 2016 
Oxic and anoxic conditions affect arsenic (As) accumulation and arsenite

\section{transporter expression in rice}

Chuan WU ${ }^{1}$, Liu HUANG ${ }^{1}$, Sheng-Guo XUE, ${ }^{1, *}$, Wei-Song PAN ${ }^{2}$, Qi ZOU ${ }^{1}$,

William HARTLEY ${ }^{3}$, Ming-Hung WONG ${ }^{4,5}$

1 School of Metallurgy and Environment, Central South University, Changsha 410083, China.

E-mail:wuchuan@csu.edu.cn

2 College of Bioscience and Biotechnology, Hunan Agricultural University, Changsha 410128,

China

3 Crop and Environment Sciences Department, Harper Adams University, Newport, Shropshire, TF10 8NB, United Kingdom

4 Consortium on Health, Environment, Education and Research (CHEER), Hong Kong Institute of Education, Tai Po, Hong Kong Special Administrative Region

5 School of Environment, Jinan University, Guangzhou, China

* Corresponding author:

Tel: +86-13787148441. E-mail address: sgxue@csu.edu.cn.

\section{ABSTRACT}

Arsenic (As) exposure from rice consumption has now become a global health issue. 
It is known that arsenite and silicic ( $\mathrm{Si}$ ) acid share the same transporters, as do arsenate and phosphate $(\mathrm{Pi})$ in rice. Growing rice aerobically, rather than in waterlogged conditions, may significantly reduce As accumulation in rice. This study aimed to investigate the effects of oxidation status on $\mathrm{Si}$ and $\mathrm{Pi}$ transporter expressions and to determine the effect of oxidation status on As uptake, translocation and speciation in four different rice genotypes. The study includes two hybrid genotypes, Xiangfengyou9 and Shenyou9586, and two conventional indica subspecies, Xiangwanxian17 and Xiangwanxian12. Results showed that oxidative treatments have significant effects on root length $(P<0.001)$ and root weight $(P<0.05)$. With the same As treatment, total As concentrations in roots were dramatically lower in oxic treatments, $(82.4$ to $242.8 \mathrm{mg} / \mathrm{kg}$ ) compared to anoxic treatments (142.9 to 265.4 $\mathrm{mg} / \mathrm{kg})(P<0.001)$. Furthermore, As treatments had a significant effect on the total As concentrations of shoots $(P<0.001)$, with higher As contents in arsenite treatments compared to arsenate treatments. In arsenate treatments, root arsenite concentrations in anoxic treatments were 1.5-2.5-fold higher than that in oxic treatments. The relative abundance of Lsi1 and Lsi2 expressions displayed a trend of down-regulation in oxic treatments compared to anoxic treatments, especially significantly different for Xiangwanxian17, Xiangwanxian12 in Lsi1 expressions, and Xiangfengyou9, Shenyou9586, Xiangwanxian17 in Lsi2 expressions $(P<0.05)$. The relative abundance of phosphate transporter expressions also presented a trend of down-regulation in oxic treatments compared to anoxic treatments, especially significantly different for Shenyou9586, Xiangwanxian17, Xiangwanxian12 in inorganic phosphate transporter 
expressions, and Xiangwanxian17 in phosphate: $\mathrm{H}^{+}$symporter family protein expression $(P<0.05)$. Different As treatment did not exert significant differences in Lsi1, Lsi2 and Pi transporters' expressions. Additionally, there were no significant genotypic differences on Lsi1, Lsi2 and phosphate transporters' expressions regardless of hybrid or conventional genotypes. The arsenic transporter expression level differences between oxic and anoxic conditions may be a possible reason for low As accumulation in rice growing in oxic compared to anoxic conditions; this may be a potential route to reduce the risk of As entering the food chain.

Key words: Arsenic; rice; speciation; arsenite transporter; arsenate transporter

\section{INTRODUCTION}

Arsenic (As) is ubiquitous in the environment and classed as a chronic carcinogen 
to humans (Shi et al., 2014; Wu et al., 2015). ${ }^{1,2}$ Arsenic exposure from water and diet has now become a global health issue (Berg et al., 2001; Zhu et al., 2008; Seyfferth et al., 2014). ${ }^{3-5}$ Over the past decades, due to anthropogenic activities such as mining, smelting and irrigation of As-contaminated groundwater, large areas of paddy soils have become contaminated with As (Liao et al., 2005; Huang et al., 2006; Shi et al., 2014). ${ }^{1,6,7}$ Furthermore, among cereal crops, rice is much more efficient at accumulating As due to its requirement for waterlogged conditions which enhance As mobility (Su et al., 2010; Somenahally et al., 2011: Jia et al., 2014). ${ }^{8-10}$ Rice is a staple food for half the world's population (Stone et al., 2006; Zhu et al., 2008; Seyfferth et al., 2014; Wu et al., 2015), ${ }^{2,5,11,12}$ its consumption being a primary source of dietary As (Meharg et al., 2009; Batista et al., 2011; Halder et al., 2014), ${ }^{13-15}$ especially in some countries of southeast Asia where rice contains a higher percentage of inorganic arsenic (iAs) (Willians et al., 2005; Zhu et al., 2008; Rahman et al., 2014). ${ }^{11,16,17}$

The As species present in soils and rice plants are mainly inorganic As [arsenite (AsIII) and arsenate (AsV)] and organic As [monomethylarsonic acid (MMA) and dimethylarsinic acid (DMA)], with inorganic As being the predominant species (Zhao et al., 2010; Zheng et al., 2013; Wu et al., 2015). ${ }^{2,18,19}$ Studies have demonstrated that oxic conditions in soils play an important role in As uptake and speciation in rice plants (Xu et al., 2008; Li et al., 2009; Somenahally et al., 2011). ${ }^{9,20,21}$ In aerobic conditions, Arsenate $[\mathrm{As}(\mathrm{V})]$ predominates, with low bioavailability, due to it being strongly adsorbed by $\mathrm{Fe}$ and $\mathrm{Al}$ (hydr)oxides (Xu et 
al., 2008; Zhao et al., 2010; Yamaguchi et al., 2014; ). ${ }^{18,20,22}$ When a soil is flooded, large concentrations of As, mainly as arsenite [As(III)], are released into the soil solution due to reductive dissolution of $\mathrm{Fe}$ (hydr)oxides and the reduction of $\mathrm{As}(\mathrm{V})$ to weekly adsorbed As(III) (Takahashi et al., 2004; Xu et al., 2008; Li et al., 2009; Zhao et al., 2010), ${ }^{18,20,21,23}$ thereby making As(III) the predominant As species in flooded paddy soils. $\mathrm{Xu}$ et al. ${ }^{20}$ (2008) and Li et al. ${ }^{21}$ (2009) observed that growing rice aerobically significantly reduced total As concentrations in the soil solution, whilst also markedly reducing total As and iAs concentrations in rice grain compared to those grown in flooded conditions. A field-scale experiment by Somenahally et al. ${ }^{9}$ (2011) revealed that intermittent flooding alleviated total As and iAs accumulation in rice grains compared to continuous flooding.

Rice, similar to most wetland plants, have developed extensive aerenchyma in their roots to adapt to flooded soil conditions (Colmer, 2003a,b). ${ }^{24,25}$ The aerenchyma supply $\mathrm{O}_{2}$ which is required for root respiration, maintenance and nutrient uptake; however approximately $30-40 \% \mathrm{O}_{2}$ is lost to the surrounding soil (Colmer, 2003a,b), ${ }^{24,25}$ in a process called radial oxygen loss (ROL) (Wu et al., 2012). ${ }^{26}$ The rate of ROL varies greatly amongst genotypes and exerts a significant effect on rhizospheric chemical processes such as iron plaque formation on root surfaces (Wu et al., 2012, 2016; Mei et al., 2012; Jia et al., 2014) 10,26-28. Genotypes with greater rates of ROL lead to increased concentrations of iron plaque formation on root surface of rice and as a result sequester As (Mei et al., 2012; Wu et al., 2012). ${ }^{26,28}$ The rate of ROL significantly influences As bioavailability and As 
uptake by rice roots (Mei et al., 2012; Pan et al., 2014; Wu et al., 2015, 2016), ${ }^{2,27-29}$ with some studies indicating that total As and iAs concentrations in rice grains were negatively correlated with the rate of ROL (Wu et al., 2012, 2016). ${ }^{26,27}$

Arsenic transfer into rice differs as a result of its speciation (Zheng et al., 2013; Zhao et al., 2010, 2013). ${ }^{18,19,30}$ In flooded paddy soils, AsIII predominates as uncharged $\mathrm{H}_{3} \mathrm{AsO}_{3}$ at $\mathrm{pH}<8$ (Zhao et al., 2010; Seyfferth and fendorf, 2012). ${ }^{18,31}$ As a silicic acid analogue, AsIII is transported into rice roots through the nodulin26-like intrinsic proteins (NIPs) responsible for the uptake of a range of small neutral molecules including Si (Ma et al., 2008; Li et al., 2009b; Wang et al., 2015) ${ }^{32-34}$. Lsi1 (OsNIP2;1) is highly expressed in rice roots and a major route to facilitate AsIII and silicic acid transport bidirectionally (Ma et al., 2006; Ma et al., 2008; Zhao et al., $2010)^{32,35,36}$. Subsequently, the efflux of AsIII from root cells to the stele is regulated by Lsi2 and this process is considered to be crucial for AsIII translocation into rice shoots (Zhao et al., 2010) ${ }^{18}$. In aerobic environments AsV is the predominant As species, and due to the oxygenation of rice roots following ROL, AsIII may be oxidized to AsV in the rhizosphere ( $\mathrm{Xu}$ et al., 2008; Zhao et al., 2010) ${ }^{18,20}$. As a phosphate analog, AsV is taken up by rice roots via phosphate transporters (Abedin et al., 2002; Chen et al., 2013), ${ }^{37,38}$ and subsequently a large quantity of $\mathrm{AsV}$ is reduced to AsIII due to arsenate reductase in rice root apex cells (Zhao et al., 2010) ${ }^{36}$. Furthermore, studies have indicated that AsIII is the predominant As species in plant tissues although AsV is initially supplied to the plant (Zhao et al., 2010a,b). ${ }^{18,36}$ Methylated As species present in rice are mainly MMA 
and DMA (Willians et al., 2005; Zavala et al., 2008; Zhu et al., 2008H), ${ }^{12,16,39}$ and studies have shown that rice plants lack the ability to methylate As; methylated As species in rice originate from microbial methylation in soils (Jia et al., 2012; Zhao et al., 2013 $)^{30,40}$. Studies have indicated that MMA and DMA can be taken up by rice roots via aquaporin channel Lsi1 (OsNIP2;1) (Li et al., 2009; Zheng et al., 2013) $)^{19,33}$. Compared with wild-type rice, the defective rice mutant in Lsi1 (OsNIP2;1) has lost approximately $80 \%$ and $50 \%$ of the uptake capacity for MMA(V) and DMA(V) respectively (Li et al., 2009) $)^{33}$.

This study aimed to investigate the effect of oxidation status on arsenite and arsenate transporter expressions and to establish the effect oxidation status has on As uptake, translocation and speciation in rice plants.

\section{MATERIALS AND METHODS}

Materials. Four rice genotypes were selected as follows: two hybrid subspecies Xiangfengyou 9 ('XFY-9'), Shenyou9586 ('SY-9586') and two indica subspecies Xiangwanxian 17 ('XWX-17'), Xiangwanxian 12 ('XWX-12'). Radial oxygen loss of XFY-9, SY-9586, XWX-17 and XWX-12 were 9.55, 10.83, 19.7 and $27.0 \mu \mathrm{mol}$ $\mathrm{O}_{2} \mathrm{~g}^{-1}$ root dry weight $\mathrm{h}^{-1}$ respectively (Wu et al., 2015) ${ }^{2}$. Seeds were all obtained from Hunan Agricultural University. Seeds were surface sterilized with a $30 \% \mathrm{H}_{2} \mathrm{O}_{2}$ solution for $15 \mathrm{~min}$, and then thoroughly washed with deionized water three times. The seeds were germinated in culture dishes on moist filter paper and germinated 
rice seedlings were then cultured in Kimura B nutrient solution (Ma et al., 2001) for 2 weeks. $^{41}$

Oxidative Treatment. After 2 weeks in the nutrient solution, uniform seedlings were selected and transplanted to 10-liter plastic vessels (six vessels, twelve plants per vessel) with Kimura B nutrient solution. The plants were then subjected to stagnant conditions (a deoxygenated nutrient solution containing $0.1 \%$, w/v, agar, which more closely resembles the flooded soil than either semi-stagnant or $\mathrm{N}_{2}$-flushed solutions, because dilute agar prevents convective movement in the solution) (Wu et al., 2012) ${ }^{26}$. Furthermore the stagnant solutions were bubbled with $\mathrm{N}_{2}$ gas for $24 \mathrm{~h}$ to ensure deoxygenation before experimental use. Nutrient solution $\mathrm{pH}$ was maintained at approximately 5.8 , with $\mathrm{KOH}$ or $\mathrm{HCl}$, and renewed once every $5 \mathrm{~d}$. Vessels were placed randomly in a greenhouse (maintained at $25^{\circ} \mathrm{C}$ during the day and $20^{\circ} \mathrm{C}$ at night, with $70 \%$ relative humidity) and natural light was supplemented with sodium light (1200 Lux), providing a photoperiod of $12 \mathrm{~h}$ light/12 h dark. Plants were cultured for 60 days.

Arsenic Treatment. Following the stagnant treatment (60 d), plants were transplanted to 2-liter plastic vessels (four plants per vessel) with Kimura B nutrient solution and contained either no arsenic, $4 \mu \mathrm{M}$ arsenate $\left(\mathrm{Na}_{2} \mathrm{HAsO}_{4}\right)$, or $4 \mu \mathrm{M}$ arsenite $\left(\mathrm{NaAsO}_{2}\right)$. The plants added to solutions containing no arsenic served as controls. Half the plants were aerated using an air pump for the entire growth 
period, while the other half were treated as stagnant as previously described. Treatments were designated as Stagnant -As (stagnant with no As addition), Aeration -As (aerated with no As addition), Stagnant +As V (stagnant with arsenate addition), Aeration + As V (aerated with arsenate addition), Stagnant+As III (stagnant with arsenite addition) and Aeration +As III (aerated with arsenite addition). There were three replicates for each treatment, with four plants for each replicate (vessels). The nutrient solution was renewed every 2 days to stabilize arsenite within the

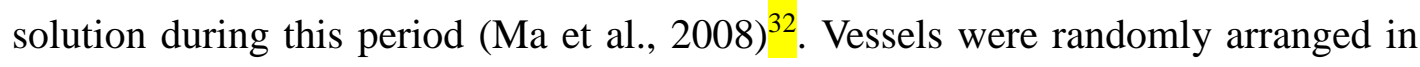
the greenhouse and plants were grown for 10 days.

Plant Analysis for Total As. Plants were harvested after 10 days and washed carefully using deionized water, then divided into roots and shoots. Root and shoot length were measured, fresh root weight determined and $0.5 \mathrm{~g}$ fresh root was collected for RNA extraction. The remaining root and shoot samples were divided equally and either oven-dried at $70^{\circ} \mathrm{C}$ to a constant weight, or freeze-dried and stored at $-20^{\circ} \mathrm{C}$ prior to As species determination.

For determination of total As concentrations, $0.5 \mathrm{~g}$ sample was weighed into a conical flask $(100 \mathrm{ml})$, and $5 \mathrm{ml}$ concentrated nitric acid added. The samples were left to digest overnight at room temperature $\left(25^{\circ} \mathrm{C}\right)$, then placed on an electric hot plate $\left(120^{\circ} \mathrm{C}\right)$ until the solution became clear. After digestion, samples were filtered and diluted to $20 \mathrm{ml}$ with deionized water into colorimetric tubes (Wu et al., 2015, 2016) $)^{2,27}$. The total As concentration (root and shoot) was determined using 
HG-AFS (AFS-8230, Beijing Jitian Instruments Co., China) (Wu et al., 2015)². For quality control, a certified reference material (bush branches and leaves, GBW07603) was used and As recovery ranged from $82.5 \%$ to $90.5 \%$.

Plant Analysis for As Speciation. For determination of As species, samples were ground under liquid $\mathrm{N}_{2}$ to ensure stabilization (Shi et al., 2013; Wu et al., $2015)^{2,42}$. Milled rice grain $(1.0 \mathrm{~g})$ was added to centrifuge tubes $(50 \mathrm{ml})$, then 20 $\mathrm{ml}$ nitric acid (1\%) was added and subsequently heated to $95^{\circ} \mathrm{C}$ for $1.5 \mathrm{~h}$. After the samples had cooled to room temperature $\left(25^{\circ} \mathrm{C}\right)$, the extracting solution was centrifuged at $5000 \mathrm{r} / \mathrm{min}$ for $10 \mathrm{~min}$ and the supernatant filtered $(0.22 \mu \mathrm{m})$. Arsenic speciation was determined using HPLC-HG-AFS (HPLC, Shimadzu LC-15C Suzhou Instruments Co., China; HG-AFS, AFS-8230, Beijing Jitian Instruments Co., China) (Shi et al., 2013; Wu et al., 2016) ${ }^{27,42}$.

RNA Isolation and RT-PCR. The total RNA was extracted from roots using an RNA extraction kit (RNeasy Plant Mini Kit, Qiagen, Germany). Total RNA (500 ng) was used for first-strand cDNA synthesis using SuperScript III Reverse Transcriptase (Invitrogen, USA). One-tenth of the reaction volume was used as the template for silicate transporters (Lsi1 and Lsi2) (Ma et al., 2008) ${ }^{32}$, phosphate transporters (inorganic phosphate transporter and phosphate: $\mathrm{H}^{+}$symporter family protein) (Li et al., 2010) $)^{43}$ and actin (internal control) amplification using PowerUp SYBR Green Master Mix (Life Technologies, USA) for real-time polymerase chain 
reaction. The two phosphate transporters were selected as they were reported for potential phosphate transportation in indica rice genotypes ( $\mathrm{Li}$ et al., 2010) ${ }^{43}$.

The primer sequences of the different genes are as follows:

Lsi1, 5'-ATCTACTTCCTGGGCCCAGT-3'(forward) and 5'-AGGAGAGCTTCTGGGAGGAG-3' (reverse) (Ma et al., 2008); ${ }^{32}$

Lsi2, 5'-ATCACCTTCCCCAAGTTCC-3' (forward) and 5'-

CAGCTCCCTCCAGTACATGC-3' (reverse) (Ma et al., 2008) ${ }^{32}$;

inorganic phosphate transporter, 5'-GTACCACCACTGGACGAC-3' (forward) and 5'-AAGTTGGCGAAGAAGAAGG-3' (reverse) (Li et al., 2010);

phosphate: $\mathrm{H}^{+}$symporter family protein, 5'-ACCACTGGACAACGAAAG-3'

(forward) and 5'-CGAAGTTGGCGAAGAAGA-3' (reverse) (Li et al., 2010) ${ }^{43}$;

Actin, 5'- GACTCTGGTGATGGTGTCAGC-3' (forward) and

5'-GGCTGGAAGAGGACCTCAGG-3' (reverse).

qRT-PCR was carried out in a StepOnePlus instrument (Applied Biosystems, USA) and relative expression normalized against Actin using the comparative CT method recommended by the instrument manufacturer. Experiments were repeated at least three times for statistical analysis of each individual experimental set. All values in the experiments were expressed as mean \pm SD.

Data Analysis. All data was analyzed in EXCEL 2007 and SPSS 19.0. Figures were created in Origin 8.0.

\section{RESULTS}

Plant Growth in Different Treatments. Root length and weight and shoot 
length were measured as plant growth parameters (Table 1). There were significant genotypic effects on root length $(P<0.001)$, root weight $(P<0.001)$ and shoot length $(P<0.001)$ of rice plants, with the greatest value, $29.14 \mathrm{~cm} /$ plant, from genotype XFY-9 in Stagnant+As III treatment and lowest value, $19.3 \mathrm{~cm} /$ plant, from genotype SY-9586 with Stagnant+As III treatments. With the exception of genotype XWX-12, shoot length was not significantly affected by oxidative treatment $(P>0.05)$. In addition, oxidative treatments had significant effects on root length $(P<0.001)$ and root weight $(P<0.05)$, being greatest for genotype XFY-9 in Stagnant+As III treatment and genotype XFY-9 in Stagnant+As V treatments (Figure ?). Additionally shoot length were smaller following arsenite treatments than with no As and arsenate treatments $(P<0.05)$.

Arsenic Accumulation in Rice following Different Treatments. Arsenic was undetectable in plants grown in As-free treatments (Table 2). Analysis of variance revealed significant genotypic effects on total As concentrations of rice roots $(P<0.001)$ and shoots $(P<0.001)$ in the same treatments. The hybrid genotypes (SY-9586 and XFY-9), with lower ROL, accumulated slightly greater As concentrations than indica genotypes (XWX-12 and XWX-17). Total As concentrations in rice roots were dramatically reduced following aeration treatments, ( 82.4 to $242.8 \mathrm{mg} / \mathrm{kg}$ ) compared to stagnant treatments $(142.9$ to $265.4 \mathrm{mg} / \mathrm{kg}$ ) $(P<0.001)$. In addition, total As concentrations in rice shoots were not significantly different between aeration and stagnant treatments, but aeration treatments slightly 
reduced total As concentrations in shoots compared to stagnant treatments. Furthermore, As treatments had a significant effect on the total As concentrations of shoots $(P<0.001)$, with higher As contents in arsenite treatments $(23.4$ to $76.9 \mathrm{mg} / \mathrm{kg})$ compared to arsenate treatments $(6.50$ to $45.3 \mathrm{mg} / \mathrm{kg})$.

Arsenic Species in Rice in Different Treatments. Methylated As species (MMA and DMA) were not detected in rice roots or shoots in any treatment (Figure 1 and 2). Regardless of arsenite or arsenate treatment, arsenite was the predominant As species in roots, accounting for $50 \%$ to $85 \%$ of extractable As (the sum of all As species), except for genotype XWX-12 grown with aeration in arsenite treatments. Arsenate concentrations were undetectable in shoots, with only arsenite detected. Results indicated that there were genotypic differences in arsenite accumulation in roots and shoots. There were no significant As treatment effects on As speciation in rice plants. Compared to stagnant treatments, aerated treatments slightly increased arsenate concentrations, but reduced arsenite concentrations in roots. In arsenate treatments especially, root arsenite concentrations in stagnant treatments were 1.5-2.5-fold higher than that in aerated treatments (Figure 1). Genotype XFY-9 in Stagnant+As V treatments contained greater arsenite concentrations $(165.8 \mathrm{mg} / \mathrm{kg})$, whilst genotype XWX-12 in Aeration+As V treatments contained the lowest arsenite concentrations $(30.04 \mathrm{mg} / \mathrm{kg})$. In addition, arsenite concentrations in shoots from stagnant treatments were $17 \%$ to $144 \%$ greater than that from aerated treatments (Figure 2, Figure 3). Arsenite concentrations ranged from 9.23 to 42.5 
$\mathrm{mg} / \mathrm{kg}$ in shoots, with lowest value found in genotype SY-9586 (Aeration+As V treatment) and greatest concentration in genotype XWX-17 (Stagnant+As III treatment).

Arsenic Transportation Expression in Different Treatments. Arsenite transporter (Lsi1 and Lsi2) and arsenate transporter (inorganic phosphate transporter and phosphate:H+ symporter family protein) expressions are presented in Figure 3. The relative abundance of Lsi1 and Lsi2 expressions presented a trend of down-regulation in stagnant treatments compared to aerated treatments, significantly different for XWX-17, XWX-12 in Lsi1 expressions, and XFY-9, SY-9586, XWX-17 in Lsi2 expressions $(P<0.05)$. Different As treatments did not exert significant differences in Lsi1 and Lsi2 expressions (Table 3). Furthermore, there were no significant genotypic differences on Lsi1 and Lsi2 expressions regardless of hybrid or conventional indica genotypes.

The relative abundance of phosphate transporter expressions also presented a trend of down-regulation in stagnant treatments compared to those that were aerated, especially significantly different for SY-9586, XWX-17, XWX-12 in inorganic phosphate transporter expressions, and XWX-17 in phosphate:H+ symporter family protein expression $(P<0.05)$. Different As treatments did not exert a significant difference in phosphate transporter expressions (Table 3). Furthermore, there were no significant genotypic differences with phosphate transporter expressions 
regardless of hybrid or conventional indica genotypes.

\section{DISSCUSSION}

Root and shoot length and fresh root weight were significantly different between the four genotypes, which is in agreement with previous studies (Wu et al., 2012, 2015) ${ }^{2,26}$. However, variation between As treatments did not exert any significant difference in either root length or weigh, only in shoot length; to some extent arsenic treatments displayed decreasing effects, which was different to other studies (Marin et al., 1993; Abedin et al., 2002). ${ }^{44,45}$ However, addition of arsenate has not revealed any significant reductions in previous studies (Marin et al., 1993; Carbonell et al., 1998; Wu et al., 2015), ${ }^{2,44,46}$ possibly due to different growing conditions and genotypes. In addition, there were significant differences in fresh root length and weight between aerated and stagnant treatments; studies have revealed that improved aeration may enhance root growth (Comis1997 ${ }^{47}$, Wu et al., $2012)^{26}$

It was also revealed that genotypic effects significantly affected As concentrations in rice roots and shoots, which is in agreement with previous studies (Wu et al., 2012; Zhao et al., 2013). ${ }^{26,30}$ In addition, there was no significant difference in As accumulation in rice roots between arsenite and arsenate treatments. $\mathrm{Wu}$ et al. ${ }^{26}$ (2012) also showed that there was no significant difference between arsenite and arsenate treatments in As accumulation in rice roots. However, there was a significant difference in As accumulation in shoots between these two As treatments 
$(P<0.001)$ and this may be due to different transportation mechanisms from root to shoot between arsenite and arsenate (Zhao et al., 2012) ${ }^{48}$. Aerated treatments showed significantly lower As accumulations in roots compared to stagnant treatments (Table 2). Norton et al. ${ }^{49}$ (2013), showed that flooding conditions substantially increased grain As content. Hu et al..$^{50}$ (2015) demonstrated in a pot experiment, that constant and intermittent flooding treatments gave 3-16 times greater As concentrations in the soil solution, than in aerobic conditions. The effect of water management in rice paddies was investigated to determine As concentrations in Japanese rice grains (Arao et al., 2009) ${ }^{51}$, revealing that flooding increased As in rice straw and grains. In a greenhouse experiment, $\mathrm{Xu}$ et al. ${ }^{20}$ (2008) investigated the dynamics of As speciation in the soil solution under both flooded and aerobic conditions, comparing As accumulation in rice shoots and grain; they revealed that As concentrations in the soil solution were 4-16 times greater under flooded conditions, whilst straw, husk and grain As concentrations were elevated, grain As being 10-15 times greater than the aerobically grown rice. Flooding may reduce soil redox potential, causing As desorption from soil particles, which greatly increases As bioavailability in both greenhouse (Xu et al., 2008; Pan et al., 2014) ${ }^{20,29}$ and field studies (Takahashi et al., $2004)^{23}$. In addition, compared to permanently flooded soil, intermittent flooding reduced As in pore-water by $86 \%$, root plaque by $55 \%$ and grain by $41 \%$ (Somenahally et al., 2011) $)^{9}$. In the present study, unlike previous investigations (Wu et al., 2015, 2016) $)^{2,27}$, hybrid genotypes with lower ROL did not reveal reduced As accumulation compared with indica genotypes with higher ROL (Table 2). The 
reduction of As accumulation in higher ROL genotypes may due to the increased iron plaque formation which sequestered more As in iron plaque, reduced As transportation to rice roots, or oxidized rhizosphere arsenite species, and caused more As sorption in rhizosphere soils (Wu et al., 2012; Pan et al., 2014) ${ }^{26,29}$.

It has been shown that AsV, AsIII, and DMA were the predominant As species detected in rhizosphere-soils and root-plaque, porewater and grain samples, respectively (Somenahally et al., 2011) ${ }^{9}$. Flooded conditions increased concentrations of dimethylarsinic acid (DMA) in grains compared to aerobic conditions (Arao et al., 2009) ${ }^{51}$. Likewise, the concentration of inorganic As was 2.6-2.9 times greater in grain from flooded treatments than in those from aerobic treatments (Arao et al., 2009) ${ }^{51}$. The present study also demonstrated that arsenite and arsenate accumulation were both lower in rice roots and shoots in aerated soils than in stagnant conditions (Figure 1,2), especially for root iAs accumulation in arsenate treatments of genotypes XFY-9, XWX-17 and XWX-12, and for shoot iAs accumulation in arsenate treatments of SY-9586. Organic As species were undetectable in both roots and shoots, which is in agreement with other studies (Chen et al., 2012) $)^{52}$.

Zhao et al. ${ }^{32}$ (2008) showed that OsNIP2;1 (Lsi1, a silicon influx transporter) is involved in arsenite uptake to root cells, while Lsi2 is involved in arsenite transport out of root cells towards the stele. However, the expression of Lsi2 in wild-type roots was abundant and not affected by arsenite exposure (Zhao et al., 2008) ${ }^{32}$, which is in agreement with present study (Table 3). Expressions of Lsi1 and Lsi2 were also not 
affected by different As treatments. Meanwhile, mRNA expressions of Lsi1 and Lsi2 in the present study resulted in a significant down-regulation in aeratied treatments compared to stagnant treatments (Table 3), which led to thereduction of total As and inorganic As in rice roots. Chen et al. ${ }^{52}$ (2012) also found that mycorrhizal inoculation reduced Lsi1 and Lsi2 expression in rice roots.

The Pi transporter plays an important role in the $\mathrm{Pi}$ absorption of plant roots (Schachtman et al. 1998), ${ }^{53}$ and arsenate and phosphate (P) share the same transporters in plants (Chen et al., 2013). ${ }^{38}$ The inorganic phosphate transporter and phosphate: $\mathrm{H}^{+}$symporter family protein were selected in this investigation as their expressions were up-regulated with low $\mathrm{P}$ stress in indica rice roots, which show potential for $\mathrm{P}$ transportation in indica rice ( $\mathrm{Li}$ et al., 2010). ${ }^{43} \mathrm{In}$ the present study, the Pi transporter expressions were significantly increased by aeration (Figure 3), providing a reduction in As accumulation in roots.At the same time, biomass of aerated treatments was also significantly increased (Table 2). Chen et al. ${ }^{38}$ (2013) found that the increased expression of Pi transporters led to significantly greater $\mathrm{P}$ concentrations and reduced arsenate concentrations in plant tissues and markedly enhanced plant biomass. It was also demonstrated that high sulfur (S) concentrations resulted in reduced transcript levels of Lsi2, and it is probable that low shoot As accumulation resulted from S application (Dixit et al., 2015). ${ }^{54}$

A possible reason for differences in transporter expressions (Figure 3) may be due to differences in stress effects (stagnant or aerated) on the signaling pathways, especially the transcriptional factors, which require further research. Shukla et al. ${ }^{55}$ 
(2015) investigated natural variations in expression of regulatory and detoxification related genes under limiting phosphate and arsenate stress in Arabidopsis thaliana; differential regulation by transcription factors may be responsible for the natural variation in Arabidopsis in response to nutrient deficiency and $\mathrm{As}(\mathrm{V})$ stress. You and

Chan $^{56}$ (2015) showed that plant cells following abiotic stress signals, such as heavy metals, transduce them through various signaling pathways including transcriptional factors. The regulation of gene expression by different transcription factors results in the expression of stress-responsive genes which confer tolerance to the environmental stress.

\section{CONCLUSIONS}

Arsenic contamination in rice has stimulated global concern due to risk of cancer formation. Understanding the mechanisms involved with As uptake in rice is critical for making practice strategies to mitigate health risks posed by As contamination. It is now known that in rice, arsenite and silicic $(\mathrm{Si})$ acid, and arsenate and phosphate (Pi) share the same transporters. Previous studies have demonstrated that growing rice aerobically may significantly reduce As accumulation in rice compared to plants grown in flooded soils. This study has aimed to investigate the effects of oxidation status on Si and Pi transporter expressions and to determine the effect of oxidation on As uptake, translocation and speciation in four different rice genotypes, two hybrid genotypes Xiangfengyou 9 and Shenyou 9586, and two Indica subspecies, 
Xiangwanxian 17 and Xiangwanxian 12.

Results have demonstrated that oxidative treatments had significant effects on root length $(P<0.001)$ and root weight $(P<0.05)$ and there were significant genotypic effects on the total As concentrations of rice roots $(P<0.001)$ and shoots $(P<0.001)$ with the same treatments. Total As concentrations in rice roots were dramatically reduced in aerated treatments, with values being 82.4 to $242.8 \mathrm{mg} / \mathrm{kg}$ compared to 142.9 to $265.4 \mathrm{mg} / \mathrm{kg}$ in stagnant treatments $(P<0.001)$. Furthermore, As treatments had a significant effect on total As concentrations for shoots $(P<0.001)$, with greater As contents in arsenite treatments compared to arsenate treatments. In arsenate treatments, root arsenite concentrations in stagnant treatments were 1.5-2.5-fold higher than that in aerated treatments.

The relative abundance of Lsi1 and Lsi2 expressions presented a trend of down-regulation in stagnant compared to aerated treatments, especially significantly different for XWX-17, XWX-12 in Lsi1 expressions, and XFY-9, SY-9586, XWX-17 in Lsi2 expressions $(P<0.05)$. The relative abundance of phosphate transporter expressions also presented a trend of down-regulation in stagnant treatments compared to aerated treatments, especially significantly different for SY-9586, XWX-17, XWX-12 in inorganic phosphate transporter expressions, and XWX-17 in phosphate:H+ symporter family protein expression $(P<0.05)$. Different As treatments did not exert a significant difference in Lsi1, Lsi2 and Pi transporter expressions. Additionally, there were no significant genotypic differences on Lsi1, Lsi2 and phosphate transporter expressions regardless of hybrid or conventional 
indica genotypes.

\section{ACKNOWLEDGMENTS}

Financial support from National Natural Science Foundation of China (No. $41201493 ; 31300815)$ is gratefully acknowledged. 
(1) Shi, T. Z.; Liu, H. Z.; Wang, J. J.; Chen, Y. Y.; Fei, T.; Wu, G. F. Monitoring arsenic contamination in agricultural soils with reflectance spectroscopy of rice plants. Environ. Sci. Technol. 2014, 48 (11), 6264-6272.

(2) Wu, C.; Zou, Q.; Xue, S. G,; Mo, J. Y.; Pan, W. S.; Lou, L. Q.; Wong, M. H. Effects of silicon ( $\mathrm{Si}$ ) on arsenic (as) accumulation and speciation in rice ( Oryza sativa L.) genotypes with different radial oxygen loss (ROL). Chemosphere. 2015, $138,447-453$.

(3) Berg, M.; Tran, H. C.; Nguyen, T. C.; Pham, H. V.; Schertenleib, R.; Giger, W. Arsenic contamination of groundwater and drinking water in Vietnam: A human health threat. Environ. Sci. Technol. 2001, 35 (13), 2621-2626.

(4) Zhu, Y. G.; Williams, P. N.; Meharg, A.A. Exposure to inorganic arsenic from rice: A global health issue? Environ. Pollut. 2008, 154 (154), 169-71.

(5) Seyfferth, A. L.; Sarah, M. C.; Schaefer, M. V.; Scott, F. Arsenic concentrations in paddy soil and rice and health implications for major rice-growing regions of Cambodia. Environ. Sci. Technol. 2014, 48 (9), 4699-4706.

(6) Liao, X. Y.; Chen, T. B.; Xie, H.; Liu, Y. R. Soil As contamination and its risk assessment in areas near the industrial districts of Chenzhou City, Southern China. Environ. Int. 2005, 31 (6), 791-798.

(7) Huang, R. Q.; Gao, S. F.; Wang, W. L.; Staunton, S.; Guo, W. Soil arsenic availability and the transfer of soil arsenic to crops in suburban areas in Fujian Province, southeast China. Sci. Total Environ. 2006, 368 (2-3), 531-541.

(8) Su, Y. H.; Mcgrath, S. P.; Zhao, F. J. Rice is more efficient in arsenite uptake and translocation than wheat and barley. Plant \& Soil. 2009, 328 (1), 27-34.

(9) Somenahally, A. C.; Hollister, E. B.; Wengui, Y.; Gentry, T. J.; Loeppert, R. H. Water management impacts on arsenic speciation and iron-reducing bacteria in contrasting rice-rhizosphere compartments. Environ. Sci. Technol. 2011, 45 (19), 8328-8335.

(10) Jia, Y.; Huang, H.; Chen, Z.; Zhu, Y. G. Arsenic uptake by rice is influenced by microbe-mediated arsenic redox changes in the rhizosphere. Environ. Sci. Technol. 2014, 48 (2), 1001-1007. 
(11) Stone, R. Arsenic and paddy rice: A neglected cancer risk? Science. 2008, 321 (5886), 184-185.

(12) Zhu, Y. G.; Sun, G. X.; Lei, M.; Teng, M.; Liu, Y. X.; Chen, N. C.; Wang, L. H.; Carey, A. M.; Deacon, C.; Raab, A.; Meharg, A. A.; Williams, P. N., High percentage inorganic arsenic content of mining impacted and nonimpacted Chinese rice. Environ. Sci. Technol. 2008, 42 (13), 5008-5013.

(13) Meharg, A. A.; Williams, P. N.; Adomako, E.; Lawgali, Y. Y.; Deacon, C.; Villada, A.; Cambell, R. C.; Sun, G.; Zhu, Y. G.; Feldmann, J. Geographical variation in total and inorganic arsenic content of polished (white) rice. Environ. Sci. Technol. 2009, 43 (5), 1612-1617.

(14) Batista, B. L.; Souza, J. M. O.; Souza, S. S. D.; Barbosa, F. Speciation of arsenic in rice and estimation of daily intake of different arsenic species by Brazilians through rice consumption. J. Hazard. Mater. 2011, 191 (1-3), 342-348.

(15) Halder, D.; Biswas, A.; Slejkovec, Z.; Chatterjee, D.; Nriagu, J.; Jacks, G.; Bhattacharya, P. Arsenic species in raw and cooked rice: Implications for human health in rural Bengal. Sci. Total Environ. 2014, 297-298, 200-208.

(16) Williams, P. N.; Price, A. H.; Raab, A.; Hossain, S. A.; Feldmann, J.; Meharg, A. A. Variation in arsenic speciation and concentration in paddy rice related to dietary exposure. Environ. Sci. Technol. 2005, 39 (15), 5531-5540.

(17) Rahman, M. A.; Rahman, M. M.; Reichman, S. M.; Lim, R. P.; Naidu, R. Arsenic speciation in Australian-grown and imported rice on sale in Australia: Implications for human health risk. J. Agr. Food Chem. 2014, 62 (25), 6016-6024.

(18) Zhao, F. J.; Mcgrath, S. P.; Meharg, A. A. Arsenic as a food chain contaminant: Mechanisms of plant uptake and metabolism and mitigation strategies. Annu. Rev. Plant Biol. 2010, 61 (4), 535-59.

(19) Zheng, M. Z.; Li, G.; Sun, G. X.; Shim, H.; Cai, C. Differential toxicity and accumulation of inorganic and methylated arsenic in rice. Plant \& Soil. 2013, 365 (1-2), 227-238.

(20) Xu, X. Y.; McGrath, S. P.; Meharg, A. A.; Zhao, F. J. Growing Rice Aerobically Markedly Decreases Arsenic Accumulation. Environ. Sci. Technol. 2008, 42 (15), 
$5574-5579$.

(21) Li, R. Y.; Stroud, J. L.; Ma, J. F.; McGrath, S. P.; Zhao, F. J. Mitigation of arsenic accumulation in rice with water management and silicon fertilization. Environ. Sci. Technol. 2009, 43 (10), 3778-3783.

(22) Yamaguchi, N.; Ohkura, T.; Takahashi, Y.; Maejima, Y.; Arao, T., Arsenic Distribution and Speciation near Rice Roots Influenced by Iron Plaques and Redox Conditions of the Soil Matrix. Environ. Sci. Technol. 2014, 48 (3), 1549-1556.

(23) Takahashi, Y.; Minamikawa, R.; Hattori, K. H.; Kurishima, K.; Kihou, N.; Yuita, K. Arsenic behavior in paddy fields during the cycle of flooded and non-flooded periods. Environ. Sci. Technol. 2004, 38 (4), 1038-44.

(24) Colmer, T. D. Aerenchyma and an inducible barrier to radial oxygen loss facilitate root aeration in upland, paddy and deep-water rice (Oryza sativa 1.). Ann. Bot. 2003, 91 (2), 301-309.

(25) Colmer, T. D. Long-distance transport of gases in plants: a perspective on internal aeration and radial oxygen loss from roots. Plant. Cell. Environ. 2003, 26 (1), $17-36$.

(26) Wu, C.; Ye, Z. H.; Li, H.; Wu, S.C.; Deng, D.; Zhu, Y. G.; Wong, M. H. Do radial oxygen loss and external aeration affect iron plaque formation and arsenic accumulation and speciation in rice? J. Exp. Bot. 2012, 63 (8), 2961-2970.

(27) Wu, C.; Zou, Q.; Xue, S. G.; Pan, W. S.; Huang, L.; Hartley, W.; Mo, J. Y.; Wong, M. H. The effect of silicon on iron plaque formation and arsenic accumulation in rice genotypes with different radial oxygen loss (ROL). Environ Pollut. 2016, 212, 27-33.

(28) Mei, X. Q.; Wong, M. H.; Yang, Y.; Dong, H. Y.; Qiu, R. L.; Ye, Z. H. The effects of radial oxygen loss on arsenic tolerance and uptake in rice and on its rhizosphere. Environ. Pollut. 2012, 165 (6), 109-117.

(29) Pan, W. S.; Wu, C.; Xue, S. G.; Hartley, W. Arsenic dynamics in the rhizosphere and its sequestration on rice roots as affected by root oxidation. J. Environ Sci. 2014, $26(4), 892-899$.

(30) Zhao, F. J.; Zhu, Y. G.; Meharg, A. A. Methylated arsenic species in rice: 
Geographical variation, origin, and uptake mechanisms. Environ. Sci. Technol. 2013, 47 (9), 3957-3966.

(31) Seyfferth, A. L.; Fendorf, S. Silicate mineral impacts on the uptake and storage of arsenic and plant nutrients in rice ( Oryza sativa L.). Environ. Sci. Technol. 2012, $46(24), 13176-13183$.

(32) Ma, J. F.; Yamaji, N.; Mitani, N.; Xu, X. Y.; Su, Y. H.; McGrath, S. P.; Zhao, F. J. Transporters of arsenite in rice and their role in arsenic accumulation in rice grain. P. Natl Acad. Sci. Usa. 2008, 105 (29), 9931-9935.

(33) Li, R. Y.; Ago, Y.; Liu, W. J.; Mitani, N.; Feldmann, J.; McGrath, S. P.; Ma, J. F.; Zhao, F. J. The rice aquaporin Lsi1 mediates uptake of methylated arsenic species. Plant Physiol. 2009, 150 (4), 2071-2080.

(34) Wang, X.; Peng, B.; Tan, C. Y.; Ma, L. N.; Rathinasabapathi, B. Recent advances in arsenic bioavailability, transport, and speciation in rice. Environ. Sci. Pollut. R. 2015, 22 (8), 5742-5750.

(35) Ma, J. F.; Tamai, K.; Yamaji, N.; Mitani, N.; Konishi, S.; Katsuhara, M.; Ishiguro, M.; Murata, Y.; Yano, M. A silicon transporter in rice. Nature. 2006, 440 (7084), 688-691.

(36) Zhao, F. J.; Ago, Y.; Mitani, N.; Li, R. Y.; Su, Y. H.; Yamaji, N.; Mcgrath, S. P.; Ma, J. F. The role of the rice aquaporin Lsi1 in arsenite efflux from roots. New Phytol. 2010, 186 (2), 392\&ndash;399.

(37) Abedin, M. J.; Feldmann, J.; Meharg, A. A. Uptake kinetics of arsenic species in rice plants. Plant Physiol. 2002, 128 (3), 1120-1128.

(38) Chen, X. W.; Wu, F. Y.; Li, H.; Chan, W. F.; Wu, C.; Wu, S. C.; Wong, M. H. Phosphate transporters expression in rice (Oryza sativa L.) associated with arbuscular mycorrhizal fungi (AMF) colonization under different levels of arsenate stress. Environ. Exp. Bot. 2013, 87 (87), 92-99.

(39) Zavala, Y. J.; Gerads, R.; Gürleyük, H.; Duxbury, J. M. Arsenic in rice: II. Arsenic speciation in USA grain and implications for human health. Environ. Sci. Technol. 2008, 42, 3861-3866.

(40) Jia, Y.; Huang, H.; Sun, G. X.; Zhao, F. J.; Zhu, Y. G. Pathways and relative 
contributions to arsenic volatilization from rice plants and paddy soil. Environ. Sci. Technol. 2012, 46 (15), 8090-8096.

(41) Ma, J. F.; Goto, S.; Tamai, K.; Ichii, M. Role of root hairs and lateral roots in silicon uptake by rice. Plant Physiol. 2001, 127 (4), 1773-1780.

(42) Shi, G. L.; Lou, L. Q.; Zhang, S.; Xia, X. W.;Cai, Q. S. Arsenic, copper, and zinc contamination in soil and wheat during coal mining, with assessment of health risks for the inhabitants of Huaibei, China. Environ. Sci. Pollut. R. 2013, 20 (12), 8435-8445.

(43) Li, L. H.; Liu, C.; Lian, X. M. Gene expression profiles in rice roots under low phosphorus stress. Plant Mol. Biol. 2009, 72 (4-5), 423-432.

(44) Marin, A. R.; Masscheleyn, P. H.; Jr Patrick, W. H. Soil redox-pH stability of arsenic species and its influence on arsenic uptake by rice. Plant \& Soil. 1993, 152 (2), 245-253.

(45) Abedin, M. J.; Cresser, M. S.; Meharg, A. A.; Feldmann, J.; Cotter-Howells, J. Arsenic accumulation and metabolism in rice (Oryza sativa L.). Environ. Sci. Technol. 2002, $36(5), 962-968$.

(46) Carbonell, A. A.; Aarabi, M. A.; Delaune, R. D.; Gambrell, R. P.;Jr, W. H. P. Arsenic in wetland vegetation: Availability, phytotoxicity, uptake and effects on plant growth and nutrition. Sci. Total Environ. 1998, 217 (3), 189-199.

(47) Comis, D. Aerenchyma - lifelines for living underwater. Agricultural Research. 1996, 45 (8), 4-8.

(48) Zhao, F. J.; Stroud, J. L.; Khan, M. A.;Mcgrath, S. P. Arsenic translocation in rice investigated using radioactive ${ }^{73}$ As tracer. Plant \& Soil. 2012, 350 (1-2), 413-420. (49) Norton, G. J.; Adomako, E. E.; Deacon, C. M.; Carey, A. M.; Price, A. H.; Meharg, A. A. Effect of organic matter amendment, arsenic amendment and water management regime on rice grain arsenic species. Environ. Pollut. 2013, 177 (4), $38-47$.

(50) Hu, P. J.; Ouyang, Y. N.; Wu, L. H.; Shen, L. B.; Luo, Y. M.; Christie, P. Effects of water management on arsenic and cadmium speciation and accumulation in an upland rice cultivar. J. Environ Sci. 2015, 27 (1), 225-231. 
(51) Arao, T.; Kawasaki, A.; Baba, K.; Mori, S.; Matsumoto, S. Effects of water management on cadmium and arsenic accumulation and dimethylarsinic acid concentrations in japanese rice. Environ. Sci. Technol. 2009, 43 (24), 9361-9367.

(52) Chen, X. W.; Li, H.; Chan, W. F.; Wu, C.; Wu, F. Y.; Wu, S. C.; Wong, M. H. Arsenite transporters expression in rice (Oryza sativa L.) associated with arbuscular mycorrhizal fungi (AMF) colonization under different levels of arsenite stress. Chemosphere. 2012, 89 (10), 1248-1254.

(53) Schachtman, D. P.; Reid, R. J.; Ayling, S. M. Phosphorus uptake by plants: From soil to cell. Plant Physiol. 1998, 116 (2), 447-453.

(54) Dixit, G.; Singh, A. P.; Kumar, A.; Singh, P. K.; Kumar, S.; Dwivedi, S.; Trivedi, P. K.; Pandey, V.; Norton, G. J.; Dhankher, O. P. Sulfur mediated reduction of arsenic toxicity involves efficient thiol metabolism and the antioxidant defense system in rice. J. Hazard. Mater. 2015, 298, 241-251.

(55) Shukla, T.; Kumar, S.; Khare, R.; Tripathi, R. D.; Trivedi, P. K. Natural variations in expression of regulatory and detoxification related genes under limiting phosphate and arsenate stress in Arabidopsis thaliana. Front. Plant Sci. 2015, 6, 898.

(56) You, J.; Chan, Z. ROS Regulation During Abiotic Stress Responses in Crop Plants. Front. Plant Sci. 2015, 6, 1092.

Table 1. Root, shoot length $(\mathrm{cm})$ and fresh root weight $(\mathrm{g} / \mathrm{plant})$ in four rice genotypes grown in different treatments (mean $\pm S D, n=3$ ).

Genotype Treatment As addition Root length Shoot length Root weight




\begin{tabular}{|c|c|c|c|c|c|}
\hline \multirow[t]{6}{*}{ XFY-9 } & Stagnant & -As & $27.98 \pm 2.73$ & $61.30 \pm 3.18$ & $3.96 \pm 0.35$ \\
\hline & & $\operatorname{As}(\mathrm{V})$ & $28.52 \pm 2.22$ & $63.20 \pm 2.23$ & $4.72 \pm 0.83$ \\
\hline & & $\mathrm{As}(\mathrm{III})$ & $29.14 \pm 2.27$ & $58.74 \pm 3.08$ & $3.49 \pm 1.04$ \\
\hline & Aeration & $-A s$ & $27.8 \pm 3.58$ & $62.60 \pm 4.92$ & $3.46 \pm 0.66$ \\
\hline & & $\mathrm{As}(\mathrm{V})$ & $27.74 \pm 3.40$ & $62.06 \pm 3.13$ & $3.43 \pm 0.85$ \\
\hline & & $\mathrm{As}(\mathrm{III})$ & $28.87 \pm 2.42$ & $59.0 \pm 4.20$ & $3.92 \pm 0.76$ \\
\hline \multirow[t]{6}{*}{ SY-9586 } & Stagnant & -As & $21.78 \pm 2.30$ & $45.90 \pm 2.62$ & $2.95 \pm 0.38$ \\
\hline & & $\mathrm{As}(\mathrm{V})$ & $20.32 \pm 1.13$ & $45.07 \pm 1.44$ & $3.04 \pm 0.42$ \\
\hline & & $\mathrm{As}(\mathrm{III})$ & $19.3 \pm 2.37$ & $45.40 \pm 3.38$ & $3.16 \pm 0.89$ \\
\hline & Aeration & -As & $25.4 \pm 3.36$ & $53.20 \pm 3.70$ & $3.18 \pm 0.56$ \\
\hline & & $\operatorname{As}(\mathrm{V})$ & $23.52 \pm 2.17$ & $49.26 \pm 4.31$ & $2.85 \pm 0.78$ \\
\hline & & $\mathrm{As}(\mathrm{III})$ & $20.93 \pm 1.61$ & $47.50 \pm 4.16$ & $2.86 \pm 0.64$ \\
\hline \multirow[t]{6}{*}{ XWX-17 } & stagnant & -As & $22.1 \pm 2.49$ & $55.9 \pm 2.61$ & $3.62 \pm 1.21$ \\
\hline & & $\operatorname{As}(\mathrm{V})$ & $19.83 \pm 1.05$ & $56.92 \pm 2.44$ & $3.62 \pm 0.79$ \\
\hline & & $\mathrm{As}(\mathrm{III})$ & $19.76 \pm 3.37$ & $53.59 \pm 2.56$ & $4.08 \pm 0.73$ \\
\hline & aeration & -As & $24.7 \pm 1.82$ & $56.04 \pm 2.99$ & $3.85 \pm 0.76$ \\
\hline & & $\mathrm{As}(\mathrm{V})$ & $25.92 \pm 3.29$ & $55.3 \pm 2.25$ & $2.97 \pm 0.68$ \\
\hline & & $\mathrm{As}(\mathrm{III})$ & $22.3 \pm 1.43$ & $56.37 \pm 3.36$ & $3.15 \pm 0.48$ \\
\hline \multirow[t]{6}{*}{ XWX-12 } & stagnant & -As & $20.5 \pm 2.59$ & $38.83 \pm 1.33$ & $2.31 \pm 0.20$ \\
\hline & & $\mathrm{As}(\mathrm{V})$ & $21.27 \pm 2.51$ & $38.90 \pm 0.85$ & $2.27 \pm 0.68$ \\
\hline & & $\mathrm{As}(\mathrm{III})$ & $21.77 \pm 1.37$ & $37.87 \pm 2.38$ & $2.20 \pm 0.40$ \\
\hline & aeration & $-A s$ & $22.94 \pm 1.97$ & $35.94 \pm 0.81$ & $2.01 \pm 0.15$ \\
\hline & & $\mathrm{As}(\mathrm{V})$ & $22.26 \pm 1.46$ & $36.90 \pm 0.65$ & $2.10 \pm 0.30$ \\
\hline & & $\mathrm{As}(\mathrm{III})$ & $22.53 \pm 1.86$ & $36.47 \pm 1.46$ & $2.27 \pm 0.58$ \\
\hline \multicolumn{6}{|c|}{ Analysis of variance } \\
\hline & $\mathrm{G}$ & & $\mathrm{P}<0.001$ & $\mathrm{P}<0.001$ & $\mathrm{P}<0.001$ \\
\hline & $\mathrm{T}$ & & $\mathrm{P}<0.001$ & NS & $\mathrm{P}<0.05$ \\
\hline & As & & NS & $\mathrm{P}<0.05$ & NS \\
\hline & $\mathrm{G}^{*} \mathrm{~T}$ & & $\mathrm{P}<0.05$ & $\mathrm{P}<0.001$ & NS \\
\hline & $\mathrm{G}^{*} \mathrm{As}$ & & $\mathrm{P}<0.05$ & NS & NS \\
\hline & $\mathrm{T}^{*} \mathrm{As}$ & & NS & NS & NS \\
\hline & $\mathrm{G} * \mathrm{~T} * \mathrm{As}$ & & NS & NS & NS \\
\hline
\end{tabular}

Table 2. As concentrations in rice roots and shoots grown in different treatments (mg/kg, mean $\pm \mathrm{SD})$. 


\begin{tabular}{|c|c|c|c|c|}
\hline & treatment & treatment & root & shoot \\
\hline \multirow[t]{4}{*}{ XFY-9 } & Stagnant & $\mathrm{As}(\mathrm{III})$ & $218.4 \pm 61.6$ & $36.3 \pm 7.6$ \\
\hline & & $\mathrm{As}(\mathrm{V})$ & $265.9 \pm 20.4$ & $28.4 \pm 3.8$ \\
\hline & Aeration & $\mathrm{As}(\mathrm{III})$ & $242.8 \pm 23.8$ & $57.2 \pm 11$ \\
\hline & & $\mathrm{As}(\mathrm{V})$ & $230.9 \pm 119.2$ & $21.9 \pm 9.2$ \\
\hline \multirow[t]{4}{*}{ SY-9586 } & Stagnant & As(III) & $142.9 \pm 8.70$ & 40. $3 \pm 0.30$ \\
\hline & & $\operatorname{As}(\mathrm{V})$ & $218.4 \pm 130$ & $25.5 \pm 12$ \\
\hline & Aeration & As(III) & $147.3 \pm 24.0$ & $34.1 \pm 11$ \\
\hline & & $\mathrm{As}(\mathrm{V})$ & $126.2 \pm 19.4$ & $21.4 \pm 8.2$ \\
\hline \multirow[t]{4}{*}{ XWX-17 } & Stagnant & As(III) & $210.3 \pm 2.0$ & 50. $1 \pm 10$ \\
\hline & & $\operatorname{As}(\mathrm{V})$ & $209.8 \pm 18.1$ & $45.3 \pm 8.8$ \\
\hline & Aeration & As(III) & $212.4 \pm 4.80$ & $76.9 \pm 8.4$ \\
\hline & & $\mathrm{As}(\mathrm{V})$ & $120.9 \pm 6.20$ & $36.7 \pm 12$ \\
\hline \multirow[t]{4}{*}{ XWX-12 } & Stagnant & As(III) & $228.4 \pm 30.9$ & $27.3 \pm 4.8$ \\
\hline & & $\operatorname{As}(\mathrm{V})$ & $198.4 \pm 14.6$ & $10.7 \pm 3.8$ \\
\hline & Aeration & As(III) & $88.80 \pm 7.50$ & $23.4 \pm 5.7$ \\
\hline & & $\mathrm{As}(\mathrm{V})$ & $82.40 \pm 3.60$ & $6.50 \pm 2.6$ \\
\hline \multicolumn{5}{|c|}{ Analysis of variance } \\
\hline \multicolumn{2}{|c|}{$\mathrm{G}$} & & $\mathrm{P}<0.001$ & $\mathrm{P}<0.001$ \\
\hline \multicolumn{2}{|c|}{$\mathrm{T}$} & & $\mathrm{P}<0.001$ & NS \\
\hline \multicolumn{2}{|c|}{ As } & & NS & $\mathrm{P}<0.001$ \\
\hline \multicolumn{2}{|c|}{$\mathrm{G}^{*} \mathrm{~T}$} & & $\mathrm{P}<0.05$ & NS \\
\hline \multicolumn{2}{|c|}{$\mathrm{G}^{*} \mathrm{As}$} & & NS & NS \\
\hline \multicolumn{2}{|c|}{$\mathrm{T}^{*} \mathrm{As}$} & & NS & $\mathrm{P}<0.05$ \\
\hline \multicolumn{2}{|c|}{$\mathrm{G}^{*} \mathrm{~T} * \mathrm{As}$} & & NS & $\mathrm{P}<0.05$ \\
\hline
\end{tabular}


Table 3. Analysis of variance of different transporter expression abundance in different treatments.

\begin{tabular}{ccccc}
\hline Analysis of variance & Lsi1 & Lsi2 $\begin{array}{l}\text { inorganic } \\
\text { phosphate } \\
\text { transporter }\end{array}$ & $\begin{array}{l}\text { phosphate: } \mathrm{H}^{+} \\
\text {symporter } \\
\text { family protein }\end{array}$ \\
\hline Genotypes (G) & $\mathrm{NS}$ & $\mathrm{NS}$ & $\mathrm{NS}$ & $\mathrm{NS}$ \\
Arsenic treatments (A) & $\mathrm{NS}$ & $\mathrm{NS}$ & $\mathrm{NS}$ & $\mathrm{NS}$ \\
Aeration treatments (T) & $\mathrm{P}<0.05$ & $\mathrm{P}<0.05$ & $\mathrm{P}<0.05$ & $\mathrm{NS}$ \\
\hline *NS, not significant at $\mathrm{P}<0.05$ level & & &
\end{tabular}

$* \mathrm{NS}$, not significant at $\mathrm{P}<0.05$ level. 

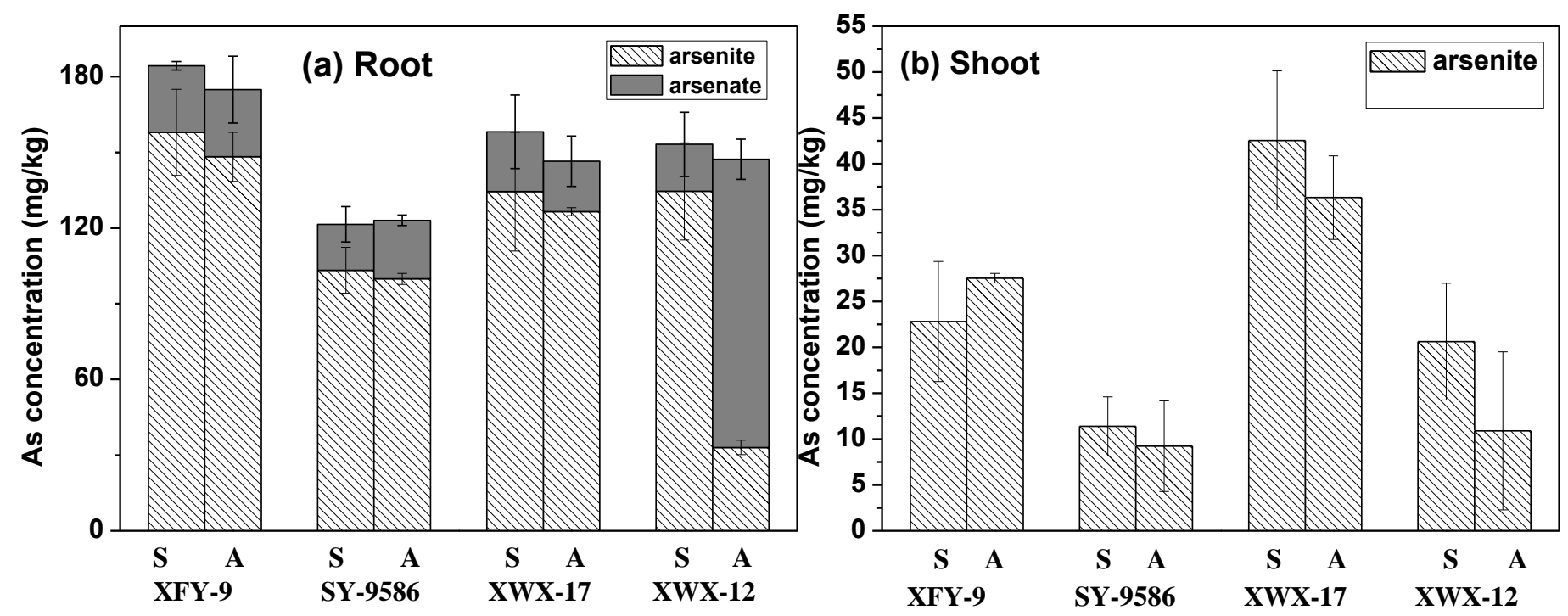

Figure 1. Arsenic speciation in roots (a) and shoots (b) of different rice genotypes in the arsenite treatment, $S$ replicates stagnant treatment, and A replicates aeration treatment. Data are mean \pm S.D. $(n=3)$. 

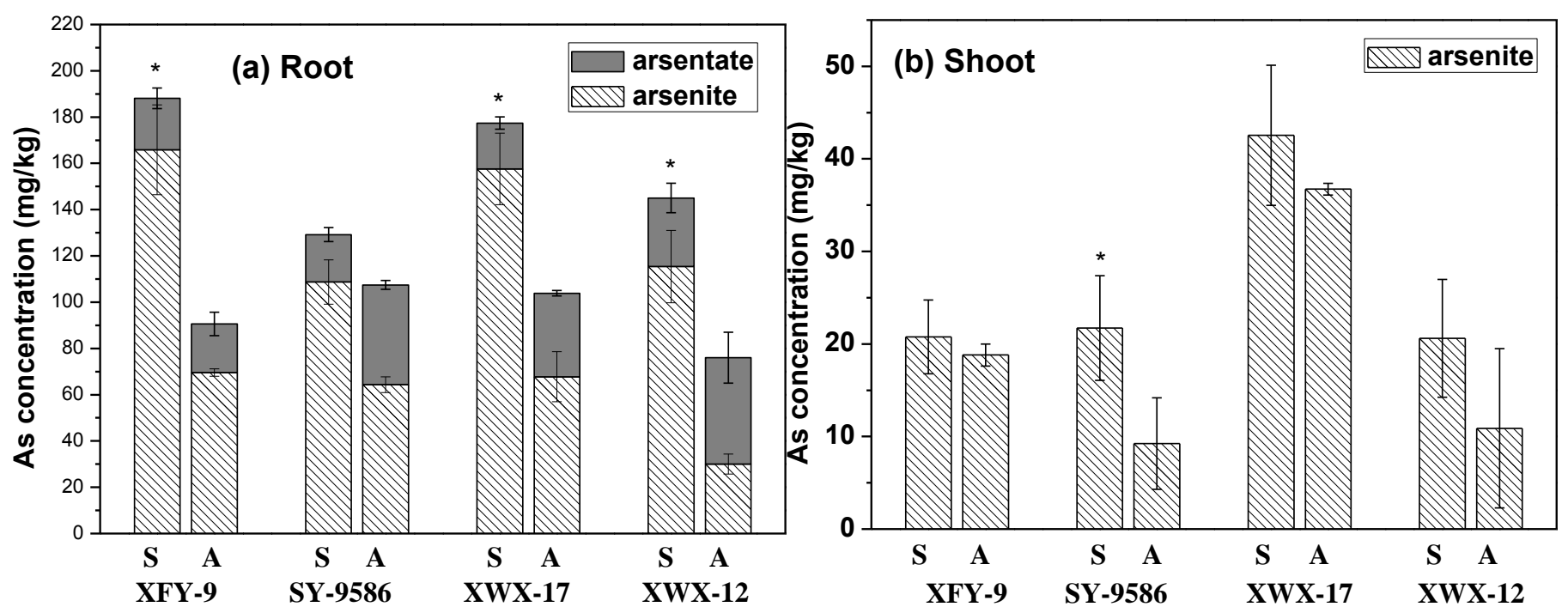

Figure 2. Arsenic speciation in roots (a) and shoots (b) of different rice genotypes in the arsenate treatment, S replicates stagnant treatment, and A replicates aeration treatment. Data are mean \pm S.D. $(n=3)$. 

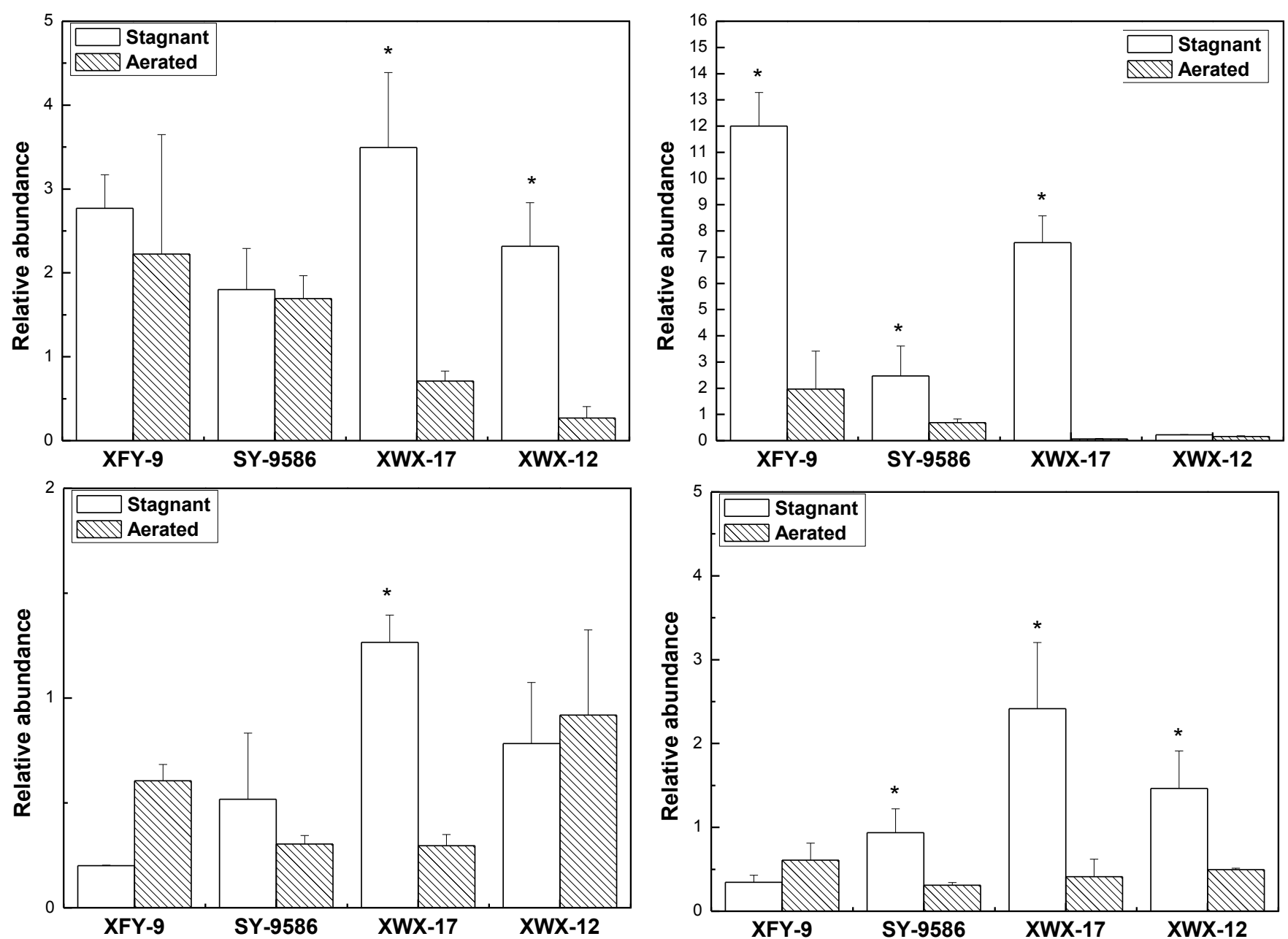

Figure 3. Relative expressions of arsenite transporters under different treatments, relative expressions of Lsi1 in different aeration conditions in the arsenite treatment of different genotypes (a), relative expressions of Lsi2 in different aeration conditions in the arsenite treatment of different genotypes (b), relative expressions of pro2 in different aeration conditions in the arsenate treatment of different genotypes (c), relative expressions of pro5 in different aeration conditions in the arsenate treatment of different genotypes (d). ' $*$ ' indicate significant difference $(\mathrm{P}<0.05)$. Data are mean \pm S.D. $(n=3)$. 


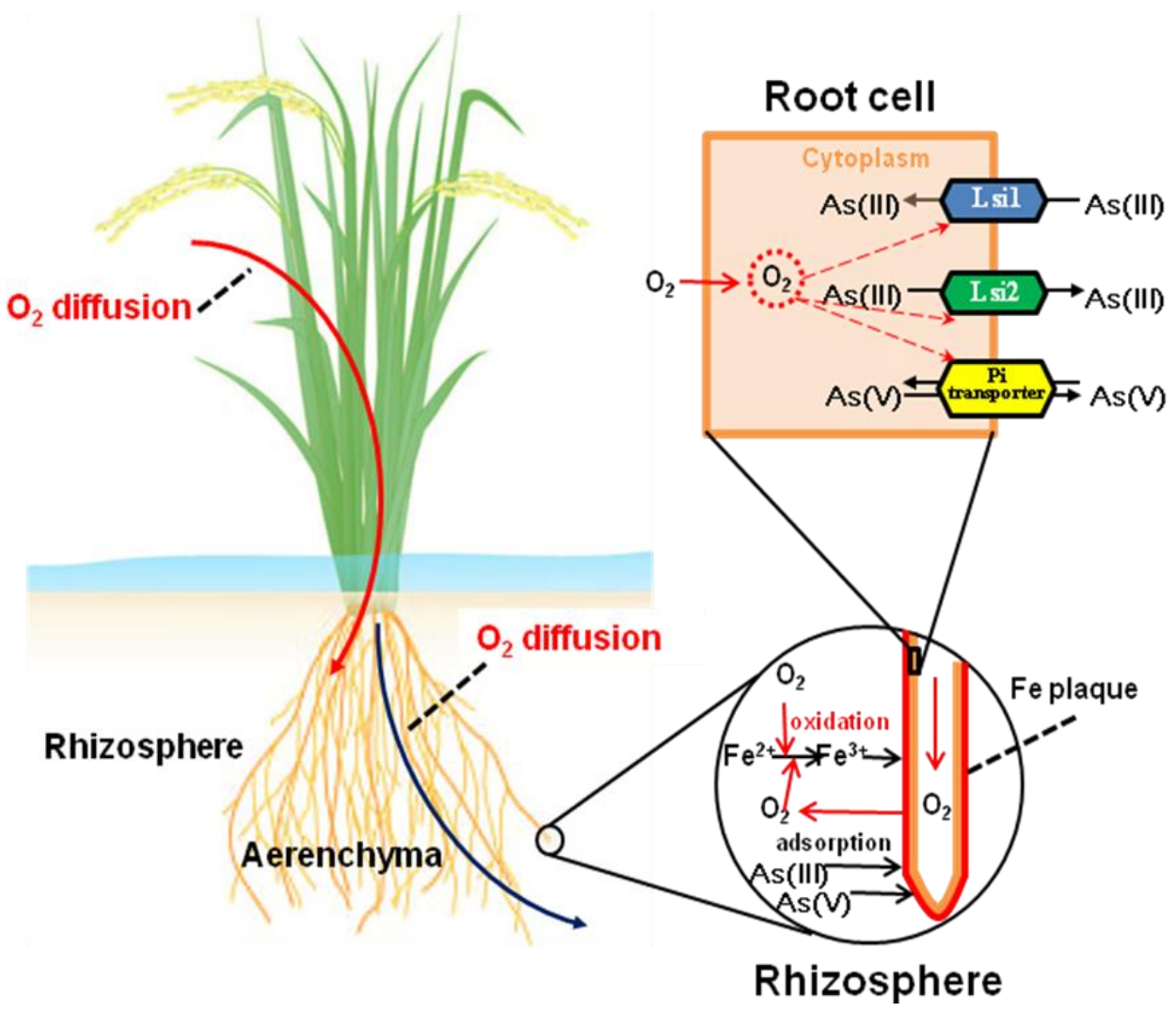

Figure 4. Oxygen diffusion in rhizosphere soils of rice plants and its relationship with arsenic mobilization, arsenic species' transportation in rice roots. 